\title{
ASPECTOS DE LA NOVELA GÓTICA EN LAS NOVELAS DE ERNESTO SÁBATO
}

\author{
Marco Antonio Fonseca Gómez \\ Universidad Central \\ crio67@hotmail.com
}

Recibido: 08/08/2018. Aceptado: 11/10/2018

doi.org/10.17533/udea.lyl.n75a07

Resumen: En este artículo se abordará el análisis de la aparición y el tratamiento particular de varios aspectos de la novela gótica que Ernesto Sábato (1911-2011) llevó a cabo en sus novelas Sobre héroes y tumbas (1961) y Abbadón el exterminador (1974). El autor se sirvió de las figuras y motivos de esta corriente literaria para sustentar una temática que fue fundamental a lo largo de su carrera y a través de la cual desarrolló su obra novelística: la irrupción de lo irracional en el plano ficcional.

Palabras claves: Gótico; novela; influencia; representación; Sábato

\section{ASPECTS OF THE GOTHIC NOVEL IN THE NOVELS OF ERNESTO SÁBATO}

\begin{abstract}
This article addresses the analysis of the appearance and the particular treatment of several aspects of the gothic novel that Ernesto Sábato (1911-2011) carried out in his novels On Heroes and Tombs (1961) and The Angel of Darkness (1974). The author used the figures and motives of this literary current to support a theme that was fundamental throughout his career and through which he developed his novelistic work: the irruption of the irrational in the fictional plane.
\end{abstract}

Keywords: Gothic; Novel; Influence; Representation; Sábato 


\section{Introducción}

Es ste ensayo pretende analizar el influjo de la corriente literaria de la novela gótica ha sido abordado por los estudiosos de este autor en forma completa y detallada. Las figuras y motivos de la novela gótica, así como su repercusión en las tradiciones literarias occidentales de los siglos XIX y XX, representaron y trataron desde diversas perspectivas el tema de la irrupción de lo irracional en un mundo regido por los parámetros de la racionalidad y de la lógica, instaurados por la modernidad. En ello podría haber un paralelo con la obra novelística y ensayística de Ernesto Sábato, interesada en reivindicar lo irracional y representar su choque con la razón y lo moderno.

Aquí hemos preferido enfocarnos en dos obras de Ernesto Sábato en las cuales se pueden detectar la presencia de aspectos de la novela gótica: la primera es su segunda novela Sobre héroes y tumbas (1961), en la que desde la ficción se hace una descripción tanto del mundo decadente de la familia Olmos, como de la locura de personaje Fernando Vidal Olmos, protagonista narrador de la tercera parte de la novela, titulada Informe sobre ciegos. En Sobre héroes y tumbas y en Informe sobre ciegos los rasgos de la novela gótica presentes constituyen un factor de suma importancia para el desarrollo de ambos textos. La segunda es Abbadón el exterminador (1974), su última novela, especie de novela total, que fusiona toda la obra anterior de Ernesto Sábato y en donde su personaje alter ego, el escritor Sabato se sumerge en un mundo irracional y fantástico de rasgos góticos, en el cual se destaca la presencia de poderes o fuerzas ocultas de tipo sobrenatural que dominan e interfieren con la existencia de los seres humanos, hasta el punto de llevarlos a la locura y la muerte.

Para el análisis de los aspectos góticos de estas dos novelas partiremos de dos premisas: en primer lugar, aparece una correspondencia con figuras y motivos de la novela gótica en la visión de universo que propone Ernesto Sábato en Sobre héroes y tumbas y Abbadón el exterminador, con toda una serie de sucesos que escapan a la razón y a la lógica, es decir, sumergiéndose en el terreno de lo inexplicable, caracterizada por ir en contravía de la producida por las tendencias materialistas y científicas que han dominado la mayor parte del pensamiento contemporáneo. En esta perspectiva, los elementos extraños, perturbadores e incluso sobrenaturales y fantásticos, representados en los aspectos góticos de las novelas, permiten ilustrar la concepción del mundo propia del autor y sirven de base al desarrollo de temas tales como el conflicto entre un pasado perturbador y un presente que lo niega en Sobre héroes y tumbas; la irrupción de la locura en Informe sobre ciegos, la tercera parte de Sobre héroes y tumbas, y la consolidación del dominio de lo irracional bajo 
una apariencia fantástica y maligna en Abbadón el exterminador. En segundo lugar, las dos obras muestran distintas maneras de representación de las figuras y motivos recurrentes de la novela gótica y de sus apariciones y modificaciones ocurridas hasta el presente, así como su influjo en la tradición literaria. Empezaremos, pues, con una breve definición de la novela gótica y de sus características; luego analizaremos la presencia de los aspectos de la novela gótica en Sobre héroes y tumbas e Informe sobre ciegos; proseguiremos igualmente con Abbadón el exterminador y, finalmente, en las conclusiones, se hará un breve contraste de las dos novelas con respecto al tratamiento de dichos aspectos.

\section{Breve definición de la novela gótica}

Como se sabe, la novela gótica es una corriente literaria que surge a finales del siglo XVIII en Inglaterra con la publicación de El castillo de Otranto (1764) de Horace Walpole. Se caracteriza por presentar historias que transcurren en una serie de escenarios, relacionados con la Edad Media o con un pasado oscuro y remoto, tales como castillos o conventos, en los que ocurren una serie de hechos misteriosos y perturbadores, en muchos casos de aparente origen sobrenatural, que van en contravía de las leyes de la razón y de la lógica, los cuales afectan de manera profunda a sus personajes. Como afirma Howard Philips Lovecraft:

This novel dramatic paraphernalia consisted first of all of the Gothic castle, with its awesome antiquity, vast distances and ramblings, deserted or ruined wings, damp corridors, unwholesome hidden catacombs, and galaxy of ghosts and appalling legends, as a nucleus of suspense and daemoniac fright. In addition, it included the tyrannical and malevolent nobleman as villain; the saintly, long persecuted, and generally insipid heroine who undergoes the major terrors and serves as a point of view and focus for the reader's sympathies; the valorous and immaculate hero, always of high birth but often in humble disguise; the convention of high-sounding foreign names, mostly Italian, for the characters; and the infinite array of stage properties which includes strange lights, damp trap-doors, extinguished lamps, mouldy hidden manuscripts, creaking hinges, shaking arras, and the like (Lovecraft, 1973, p. 22).

La aparición de lo sobrenatural y de lo fantástico como los factores desencadenantes de la trama de estas obras literarias y el uso constante de los personajes, acciones y escenarios mencionados anteriormente serán característicos y recurrentes a lo largo del desarrollo de la novela gótica. Estos elementos irán evolucionado de acuerdo con las distintas maneras y particularidades de plasmarlos por los autores que van a cultivar el género, tales como Anne Radcliffe en Los misterios de Udolfo (1794), o Matthew Gregory Lewis en El monje (1796), entre otras novelas, quienes 
agregan nuevas maneras, formas y motivos de aproximarse a lo gótico, tales como la explicación racional de los fenómenos sobrenaturales en el caso de las novelas de Radcliffe, o la presencia de la figura del diablo y de lo demoníaco en el caso de la novela de Lewis, las cuales enriquecen la tradición iniciada por Walpole con $E l$ castillo de Otranto. Con respecto a esto, Howard Philips Lovecraft afirma:

All this paraphernalia reappears with amusing sameness, yet sometimes with tremendous effect, throughout the history of the Gothic novel; and is by no means extinct even today, though subtler technique now forces it to assume a less naive and obvious form. An harmonious milieu for a new school had been found, and the writing world was not slow to grasp the opportunity (Lovecraft, 1973, p. 23).

Así, pues, un buen ejemplo de esta ambientación lo podemos ver en el motivo del pasadizo o laberinto subterráneo que aparece en El castillo de Otranto por primera vez, para luego generalizarse en toda la novela gótica posterior. Recuérdese que Isabella, la prometida del difunto Conrad, hijo de Manfred y señor de Otranto, es perseguida por éste a través de los pasadizos del castillo. Este recorrido genera en Isabella una sensación de terror y angustia, potenciada por la atmósfera siniestra, el silencio y los sonidos que la rodean:

The lower part of the castle was hollowed into several intricate cloisters; and it was not easy for one under so much anxiety to find the door that opened into the cavern. An awful silence reigned throughout those subterraneous regions, except now and then some blasts of wind that shook the doors she had passed, and which, grating on the rusty hinges, were re-echoed through that long labyrinth of darkness. Every murmur struck her with new terror (Walpole, 2014, p. 13).

Este motivo del pasadizo o del laberinto subterráneos y del miedo y la inquietud que causan en los que los recorren, así como la creación de ambientes y atmósferas perturbadores relacionada con esta clase de sitios que se supone, por diversas razones, no deben ser frecuentados, potenciando así su aura de espacios malditos o prohibidos, será retomado por Ernesto Sábato en Sobre héroes y tumbas y Abbadón el exterminador para representar el descenso de los personajes Fernando Vidal Olmos y Sabato a las cloacas y túneles del subsuelo de Buenos Aires, lugares en donde habita la secta demoníaca de los ciegos que supuestamente controla y rige el mundo ficticio en estas novelas. Esto permitiría comprobar un fuerte vínculo con la obra novelística de Ernesto Sábato y la novela gótica, el cual será analizado con más profundidad y de manera detallada a lo largo de este artículo. Igualmente, también se podría afirmar de manera hipotética para futuras investigaciones, que en la traducción al inglés de las tres novelas del escritor argentino, traducidas como The Tunnel, (El túnel), On Heroes and Tombs (Sobre héroes y tumbas) y The Angel of Darkness (Abbadón el 
exterminador) habría una posible correspondencia con los temas y motivos de la novela gótica inglesa de finales del siglo XVII, particularmente por la aparición de lo fantástico, de lo irracional, así como por la irrupción del pasado que pugna por salir y está oculto.

Finalmente, lo más importante de la novela gótica es que, a partir del siglo XVIII, ha permitido a escritores y artistas de distintas latitudes, incluyendo a numerosos autores latinoamericanos de los siglos XIX y XX, la expresión de las pulsiones y fuerzas irracionales de la mente y de la psique humanas, bajo el aspecto de lo fantástico, de lo inquietante y de lo terrorífico, fuerzas que irrumpen de repente en la cotidianidad de forma abrupta y transgresora, ya sea en el pasado o en el presente, para trastocar el orden establecido de manera definitiva; esto iría a favor de lo que la sociedad no permite que sea representado, reprimiéndolo y prohibiéndolo, aquello que supuestamente no se debe mencionar por ser tabú, tal es el caso de los deseos incestuosos $\mathrm{u}$ homicidas.

\section{Aspectos góticos presentes en Sobre héroes y tumbas}

Recuérdese brevemente que el argumento primero de Sobre héroes y tumbas narra la historia del amor turbulento y enfermizo entre dos jóvenes argentinos, Martín del Castillo y Alejandra Vidal Olmos, en la primera década de los años cincuenta del siglo XX en Buenos Aires, durante el final convulso del primer período de gobierno del coronel Juan Domingo Perón. Además de esta historia principal, la tercera parte de Sobre héroes y tumbas, titulada Informe sobre ciegos, es un relato independiente del resto de la obra, escrito en primera persona por Fernando Vidal Olmos, padre de Alejandra. Fernando Vidal Olmos es un personaje demente y paranoico que cree que el mundo está regido por una secta de ciegos y pretende demostrar con el Informe, texto lleno de alucinaciones y pesadillas originadas en su mente enferma, que su teoría es cierta. Vidal Olmos es asesinado por su hija, con quien ha sostenido relaciones incestuosas; después de matar a su padre, Alejandra se suicida, prendiendo fuego al antiguo mirador de la casa familiar. A raíz de este homicidio es descubierto el manuscrito de Informe sobre Ciegos. Posteriormente, Martín del Castillo intenta comprender quiénes fueron Alejandra y Fernando Vidal Olmos con la ayuda de un amigo de ambos, el intelectual Bruno Bassán. Al final de la novela Martín huye de Buenos Aires hacia la Patagonia después de haber intentado suicidarse. Asimismo, cabe destacar también que la mención de las tumbas en el título de la novela se refiere al viaje a ese mundo onírico e irracional del pasado glorioso de la Argentina que representan los miembros de la familia Olmos, travesía que emprende Martín del Castillo cuando conoce a Alejandra Vidal Olmos y que se consolida con la aparición del delirante Informe sobre ciegos de Fernando Vidal Olmos. Blas Matamoro 
define este descenso a lo irracional y a lo histórico que simboliza la familia Olmos de la siguiente manera:

Sobre héroes y tumbas puede leerse como una gran catábasis, un viaje al mundo inferior de los muertos (mundo, por lo tanto, fundamental y sagrado) que está señalado en el propio título, donde se alude a la tumba de los héroes, espacio sepulcral donde yacen los héroes muertos de la antigüedad argentina y los héroes de la muerte, del Tánatos, de la necrofilia, de la corrupción y de la disolución (Matamoro, 1983, p. 486).

Por consiguiente, Sobre héroes y tumbas se puede leer desde el principio, o sea, a partir del encuentro de Martín y Alejandra en el parque Lezama y de la posterior inmersión de Martín del Castillo en el mundo decadente y fantasmagórico de la familia Olmos, como una obra con varios rasgos góticos, tales como el incesto, la necrofilia y la presencia de la muerte y de lo irracional, que se combinan con la realidad de la Argentina de los años cincuenta del siglo pasado. El reverso de ese ámbito cotidiano es ese escenario gótico, cargado de irracionalismo, al que desciende el lector, descrito y representado en la novela con base en los delirios, pesadillas y alucinaciones de Alejandra, Fernando Vidal Olmos y el resto de la familia Olmos, la cual Ernesto Sábato escenifica con gran intensidad y choca con la supuesta realidad lógica y racional de la modernidad.

Un buen ejemplo de cómo se escenifica en Sobre héroes y tumbas este influjo de la novela gótica es la familia Olmos y el ambiente donde habita. Cuando en la primera parte de la novela Martín va con Alejandra al viejo caserón de la familia Olmos y le escucha las tétricas historias de la familia, el joven Martín siente que ha penetrado en un mundo fantasmal, de pesadilla, que parece no regirse por las leyes de la cotidianidad:

Y cabeceando empezó a dormitar mientras Martín estaba paralizado por un silencioso y extraño pavor en medio de aquella pieza casi oscura, con aquel viejo casi centenario, con la cabeza del coronel Acevedo en la caja, con el loco que podía andar rondando por ahí. Pensaba: lo mejor es que salga. Pero el temor de encontrarse con el loco lo paralizaba. Y entonces se decía que era preferible esperar la vuelta de Alejandra que no tardaría, que no podía tardar, ya que sabía que él nada podía hacer con aquel viejo. Sentía como si poco a poco hubiese ido ingresando en una suave pesadilla en que todo era irreal y absurdo (Sábato, 2000, p. 97).

Estas historias se originan en la atmósfera fantasmal e irreal de la antigua quinta de los Olmos, que parece abandonada en medio de fábricas, y son enfatizadas con la presencia de personajes inquietantes y anormales tales como el tío demente Bebe, quien toca el clarinete en medio de la noche de manera intempestiva y caótica, o la aparición de la sirviente indígena Justina, enigmática y silenciosa, que se asemeja 
a un fantasma. Se trata, pues, de un ambiente necrofílico, de dominio de la muerte, siendo este otro de los temas por excelencia de la novela gótica, así como del romanticismo en general. Así lo recalca Blas Matamoro:

Los Vidal simbolizan una clase que sobrevive a su propia muerte, que ocupa un espacio fuera del tiempo histórico, donde ya no cabe ninguna intervención. Martín está hechizado por ella, pero este hechizo es —otra vez romántico - el de la necrofilia (Matamoro, 1983, p. 489).

También es importante para la consolidación de lo gótico en la novela el relato del bisabuelo Pancho, quien cuenta a Martín, instado por Alejandra, entre otros hechos históricos, la historia de su tío abuelo, el comandante Bonifacio Acevedo, asesinado en el siglo XIX por las fuerzas represivas del dictador Juan Manuel de Rosas, las cuales arrojaron su cabeza a la sala de su casa por la ventana. Este hecho originó el fallecimiento de su esposa, en tanto que su hija Escolástica recogió la cabeza de su padre y la mantuvo momificada hasta su muerte en 1932, mientras vivía aislada en un estado de demencia en el altillo de la quinta. La familia Olmos, a los ojos de Martín, parece no corresponder a la misma realidad a la que él pertenece. Esto se refuerza con la extrañeza y el desconcierto que la narración del bisabuelo Pancho produce en él, lo que provoca las siguientes reflexiones en Martín:

Martín volvió a mirar hacia la puerta, pero ningún ruido se oía. ¿Dónde está Alejandra? ¿Qué hacía en su pieza? También pensó que si no se había ido era por no dejar solo al viejo, que ni siquiera lo oía y tal vez ni lo veía: el viejo seguía su existencia subterránea y misteriosa, de él ni de nadie que viviera en ese tiempo, aislado por lo años, por la sordera y la presbicia, pero sobre todo por la memoria del pasado, que se interponía como una oscura muralla de sueño viviendo en el fondo de un pozo, recordando negros, cabalgatas, degüellos y episodios de la legión. No se había quedado por consideración al viejo, sino porque estaba inmovilizado por una especie de temor a aquellas regiones de la realidad en que parecía habitar el abuelo, el loco y hasta la propia Alejandra. Territorio misterioso e insano, disparatado y tenue como los sueños, tan sobrecogedor como los sueños (Sábato, 2000, p. 103).

Estas reflexiones de Martín hacen aparecer en su discurso una serie de temas y motivos que podrían estar relacionados con la novela gótica, tales como lo fantástico, lo nocturno, los sueños, etcétera. Estos temas y motivos que utiliza Sábato para representar el mundo fantástico de la familia Olmos parecían proceder, en este caso, de la obsesión de la novela gótica por lo oscuro que encarna lo irracional, escenificada frecuentemente de manera metafórica en sus narraciones por medio del símbolo de la noche y de las tinieblas, escenario ideal para la exploración de lo inconsciente, tal como lo afirma Beatriz González Moreno: 
La noche, las tinieblas, se convierten en un espacio emblemático de la imaginación, una región donde las leyes imperantes no son las de la razón, sino que tienen su origen en la libre asociación, sin necesidad de atender a la ley natural (Gónzalez Moreno, 2007, p. 117).

Según Miriam López Santos, la noche y de forma más específica su oscuridad y su negrura, sus tinieblas, conducen en las novelas góticas a un espacio en donde rigen lo desconocido y lo incomprensible, aspecto que se puede ver en los fragmentos anteriormente citados de Sobre héroes y tumbas:

Similar efecto tiene en las novelas el llamado espacio de la noche que se opondría al espacio del día. Frente a la claridad del día, la noche distorsiona la geografía que conocemos, los límites y los objetos se alternan de manera amenazante y estas transformaciones misteriosas contribuyen a intensificar la sensación de terror en los personajes. Percibimos la contraposición del espacio del día frente al de la noche en cada pasaje de las novelas góticas (López Santos, 2010, pp. 287-288).

Así pues, Ernesto Sábato parece retomar en Sobre héroes y tumbas estos temas y motivos provenientes de la imaginería gótica de los siglos XVIII y XIX, combinándolos y reactualizándolos con su visión pesimista y trágica de la historia de Argentina, representada en la ficción por el trágico destino de la familia Olmos. Así, cuando Martín del Castillo logra salir de la casona de los Olmos, considera que su experiencia ha sido una suerte de sueño absurdo y fantasmagórico, una inmersión en un mundo alejado de la realidad convencional, similar a la experiencia que anhelaban alcanzar en sus obras los novelistas góticos:

Volvió unos pasos hacia la casa y luego se detuvo nuevamente. Miró hacia la verja mohosa, como si esperara algo. ¿Qué? A la luz del día el caserón era todavía más disparatado que de noche, porque con sus paredes derruidas y desconchadas, con los yuyos creciendo libremente en el jardín, con su reja enmohecida y su puerta casi caída contrastaba con más fuerza que de noche con las fábricas y las chimeneas que se destacaban detrás. Como un fantasma es más absurdo de día (Sábato, 2000, p. 109).

Estos pensamientos de Martín se conectan inmediatamente con las situaciones vividas esa misma noche con Alejandra y su familia, acontecimientos que bordean la locura y lo insano, todos ellos rasgos de la novela gótica por excelencia, y que Martín es incapaz de comprender y explicar de una manera racional y satisfactoria:

La noche que había pasado en aquella casa se le aparecía ahora, a la luz del día, como un sueño: el viejo casi inmortal; la cabeza del comandante Acevedo metida en aquella caja de sombreros; el tío loco con su clarinete y sus ojos alucinados; la vieja india, sorda o indiferente a cualquier cosa, hasta el punto de no molestarse en saber quién era y qué 
hacía un extraño que salía de las habitaciones y que luego subía al Mirador, la historia del Capitán Elmtress; la historia increíble de Escolástica y su locura; y sobre todo, la propia Alejandra (Sábato, 2000, p. 109).

Por ello, se presentaría en Sobre héroes y tumbas un tema que fue fundamental en la novela gótica, a saber, la irrupción violenta de vestigios del pasado, de un pasado que por diversas razones no se quiere recordar y que debe permanecer en el olvido y en el secreto para no alterar el presente. Este hecho termina por trastocar todo lo que se creía normal y que podía ser explicado por la racionalidad y la lógica, creando un ambiente inquietante que termina por sacar aquello que estaba oculto por transgredir la modernidad, es este caso el mundo delirante y decadente de la familia Olmos, descubierto por Martín del Castillo en plena Argentina del siglo XX, poblado por el recuerdo constante de crímenes y hechos perturbadores, tales como la conservación de la cabeza del Comandante Bonifacio Acevedo por su hija demente Escolástica Olmos, durante casi un siglo, o posteriormente, el descubrimiento de la relación incestuosa de Alejandra Vidal Olmos con su padre Fernando Vidal Olmos que terminará de manera trágica en el trascurso de la novela. Según Roberto Cueto esta es la característica fundamental de la novela gótica:

En definitiva, lo gótico habla de la imposibilidad de escapar de un pasado, o muestra como ese plácido presente es víctima de terroríficas transgresiones, ya sean de tipo moral, social o natural: torturas, crímenes, secuestros, violaciones, incestos, injerencias sobrenaturales, presencias monstruosas y deformidad física (Cueto, 2010, p. 40).

Por eso, según Gabriel Eljaiek Rodríguez, la novela gótica será el ámbito por excelencia de la búsqueda de lo que él denomina como lo otro, o sea, lo prohibido e irrepresentable a través del horror que genera ese miedo a lo irracional, a lo inconsciente, que está agazapado en lo profundo de la mente humana y que se puede desatar en cualquier momento, conduciendo a lo desconocido y a lo incomprensible, representado en este caso, por el miedo y la angustia que siente Martín ante la familia Olmos:

El gótico, como herramienta que permite la movilidad lingüística, geográfica y temporal de aquello considerado como otro, se complejiza con la introducción y utilización del horror como tema y dispositivo narrativo, que busca generar una sensación en los lectores, comúnmente miedo, pero también angustia, repulsión, terror (Eljaiek Rodríguez, 2017, p. 28).

Aquí se podría considerar que entra la idea de lo siniestro u ominoso tal como fue formulada por Sigmund Freud, denominada das Unheimlich en alemán, como aquello que está oculto y no debe ser revelado, pero termina manifestándose en contra de lo familiar y natural, en alemán das Heimlich: 
Lo Unheimlich, lo siniestro, forma uno de estos dominios. No cabe duda de que dicho concepto está próximo a los de lo espantable, angustiante, espeluznante, pero no es menos seguro que el término se aplica a menudo en una acepción un tanto indeterminada, de modo que casi siempre coincide con lo angustiante en general (Freud, 1992, p. 219).

Por lo tanto, lo Unheimlich formula la irrupción de lo inquietante en lo familiar, es decir, en este caso de las fuerzas de lo irracional que se pueden desatar en el plano narrativo a través de lo fantástico o de lo insólito, y que van en contravía de lo que se puede explicar por medio de la razón y de la lógica, es decir, se trata de una clara transgresión de los parámetros establecidos del pensamiento racional en el relato:

Unheimlich tan sólo sería empleado como antónimo del primero de estos sentidos, y no como contrario del segundo. El diccionario de Sanders nada nos dice sobre una posible relación genética entre ambas acepciones. En cambio, nos llama la atención una nota de Schelling, que enuncia algo completamente nuevo e inesperado sobre el contenido del concepto unheimlich: Unheimlich sería todo lo que debía haber quedado oculto, secreto, pero que se ha manifestado (Freud, 1992, pp. 224-225).

Si se toma en cuenta lo expresado por Freud en su definición de lo siniestro, rasgo característico de las novelas góticas, consideramos que en la aparición de hechos perturbadores o extraños que experimenta Martín del Castillo en su estadía en la quinta de la familia Olmos durante la primera parte de Sobre héroes y tumbas, titulada El dragón y la princesa, se encuentra la presencia de lo angustiante. En la medida en que aparece en los miembros de la familia Olmos y en las situaciones en las que se encuentran, esa deformación de lo cotidiano y de lo habitual que refleja todo lo reprimido del inconsciente, lo que no se atreve a aceptar ni a exteriorizar como la posibilidad de una cabeza momificada de una persona asesinada, lo que se vuelve extraño y amenazador por su aparición inesperada, recupera la característica fundamental de lo gótico en literatura. Esto desafía los mecanismos represores de la mente humana, transformándose en lo siniestro que conduce a la angustia según Umberto Eco:

Freud admitía con Jentsch que sin duda lo siniestro se presenta como antítesis de todo lo que es confortable y tranquilo, pero observaba que no todo lo inusual es siniestro; recordando a Schelling, afirmaba que resulta siniestro aquello que constituye un regreso de la represión, esto es, algo olvidado que emerge de nuevo y, por tanto, algo inusual que reaparece tras la supresión de alguna cosa conocida que había perturbado nuestra infancia personal o la infancia de la humanidad (como el retorno de fantasías primitivas sobre los espectros y otros fenómenos sobrenaturales) (Eco, 2013, pp. 311-312). 
Por ello, en Sobre héroes y tumbas se construiría una realidad delirante y fantástica, similar a las de las novelas góticas, a través de lo perturbador de sus situaciones y personajes, y en la que podrían salir a relucir los miedos y temores humanos, reprimidos y prohibidos según Freud por el miedo a la sexualidad, en forma de situaciones insólitas y angustiosas. Así lo define Umberto Eco:

Coherente con sus principios teóricos, Freud retrotraía la represión individual a temores referentes al sexo y especialmente al temor a la castración; de ahí que citara como hechos siniestros situaciones 'góticas' como miembros separados del cuerpo, cabezas cortadas o pies que bailan solos (Eco, 2013, p. 312).

Este ambiente gótico también se desarrolla en Sobre héroes y tumbas en la tercera parte de la novela, el Informe sobre ciegos, escrito y protagonizado por Fernando Vidal Olmos. En el primer párrafo del primer capítulo de este texto autónomo de la novela, el cual mantiene una estrecha vinculación con ésta y aunque su narración, historia y personajes no formen parte de la totalidad del relato de Sobre héroes y tumbas, el mismo Fernando Vidal Olmos, protagonista y narrador de la obra, empieza su narración tratando de recordar cuándo comenzó su investigación, y ello a sabiendas de que terminará siendo asesinado por su hija Alejandra. Recuérdese que Vidal Olmos escribe su delirante texto sobre su obsesión con los ciegos en forma de un supuesto informe científico: este empieza, precisamente como una indagación en su inconsciente, es decir, en su irracionalidad: "Recuerdo perfectamente, en cambio, los comienzos de mi investigación sistemática (la otra, la inconsciente, acaso la más profunda, ¿cómo puedo saberlo?)" (Sábato, 2000, p. 289). El discurso de Vidal Olmos al narrar el informe se caracteriza por su intento de convencer al lector desde el principio de que todo lo que cuenta es real y ocurrió en verdad. Para ello, apela al rigor de la razón y de la lógica, a la supuesta cientificidad del Informe sobre ciegos en su escritura y en sus planteamientos. Sin embargo, la supuesta razón que exhibe Vidal Olmos para legitimar su investigación está alimentada por la irracionalidad que lo controla y lo domina por completo. Este influjo se hace patente por la utilización constante de planteamientos que se hunden en los terrenos de lo onírico y de lo irracional, tales como la descripción de sueños y de pesadillas y el uso de corrientes de pensamiento como el ocultismo o la magia negra, aspectos todos ellos recurrentes de la novela gótica y que son definitivamente contrarios al método científico, puesto que su campo de estudio, es decir, los fenómenos paranormales, no pueden ser comprobados ni esclarecidos por la metodología científica:

La investigación, claro, terminó, donde debía empezar de verdad: en el umbral inviolable. En cuanto al dominio por medio de los sueños, las pesadillas y la magia negra, no vale ni siquiera demostrar que la Secta tiene para ello a su servicio a todo el ejército de 
videntes y de brujas de barrio, de curanderos, de manos santas, de tiradores de cartas y de espiritistas: muchos de ellos, la mayoría, son meros farsantes; pero otros tienen auténticos poderes y, lo que es curioso, suelen disimular esos poderes bajo la apariencia de cierto charlatanismo, para mejor dominar el mundo que los rodea (Sábato, 2000, pp. 298-299).

Por ello, se podría afirmar que, en las declaraciones de Vidal Olmos en el Informe sobre ciegos, hay una correspondencia con el uso de los motivos y figuras de la novela gótica referentes a lo sobrenatural como una representación distinta de la realidad, así como una crítica a la manera en que la realidad se representa en la literatura. En efecto, la novela gótica pone en tela de juicio lo que se da por sentado como real, por medio del uso de lo fantástico y de lo inexplicable, estrategia que también utiliza Ernesto Sábato en sus novelas, tal como lo afirma Pablo Sánchez López, con el fin de resaltar los aspectos irracionales del ser humano y cómo estos inciden en la construcción de la realidad que lo rodea:

Desde esta perspectiva, podemos considerar que la trilogía narrativa de Sábato acentúa progresivamente el desafío a las normas del realismo y a la comprensión objetiva y racional de nuestro mundo real. En ese descrédito del realismo tienen una importancia central los elementos sobrenaturales y más exactamente, su aceptación y normalización, como base de una poética y una cosmovisión que el novelista argentino defiende tenaz y explícitamente (también en ensayos como El escritor y sus fantasmas) (Sánchez López, 2006, p. 89).

Así, en su narración, Vidal Olmos recurre a una amplia gama de motivos y símbolos de carácter gótico tales como las pesadillas o los fantasmas, que evocan su inmersión sin salida en las creaciones delirantes de su mente y su incapacidad para representarlas, de tal forma que estas no constituyan un peligro para su salud mental, ya de por sí totalmente deteriorada:

Muchos años tuvieron que transcurrir para que pudiera sobrepasar las defensas exteriores. Y así, paulatinamente, con una fuerza tan grande y paradojal como la que en las pesadillas nos hacen marchar hacia el horror, fui penetrando en las regiones prohibidas donde empieza a reinar la oscuridad metafísica, vislumbrando aquí y allá al comienzo indistintamente, como fugitivos y equívocos fantasmas, luego con mayor y aterradora precisión, todo un mundo de seres abominables (Sábato, 2000, pp. 291-292).

Esto genera a lo largo del Informe sobre ciegos la construcción de una atmósfera gótica de sueños, pesadillas y alucinaciones, acorde con el carácter transgresor del texto que nos alerta del peligro de negar las potencias de lo irracional, pero también de permitir que estas se apoderen del control de nuestra mente, tal como le ocurre a Fernando Vidal Olmos en su locura. Así lo entiende y afirma el personaje Bruno 
Bassán en la cuarta parte de Sobre héroes y tumbas, titulada Un Dios desconocido, al referirse a las páginas del Informe sobre Ciegos como la representación de los delirios de un loco que no supo poner límites a su locura: "Parecen revelar sus momentos de alucinaciones y de delirio, momentos que en rigor abarcaron casi toda la última etapa de su existencia, esos momentos en que se encerraba o en que desaparecía" (Sábato, 2000, p. 460). Esta idea del universo oscuro y tenebroso de los ciegos tiene su origen en unas muy profundas obsesiones y neurosis que Vidal Olmos ha acumulado a lo largo de su vida, relacionadas con el mal y con las prohibiciones que los seres humanos deben soportar desde su infancia. La pasión incestuosa por su hija que le remite a la madre de ésta, Georgina Olmos, prima hermana suya, y a su vez a la obsesión incestuosa hacia su propia madre, Ana María Olmos, refuerza el carácter psicótico de Vidal Olmos, detona la creación de la entidad demoníaca y maligna de la secta de los ciegos, y genera un hilo conductor en la novela por medio del motivo del incesto que se transmite de generación en generación. Aquí reaparecería otro motivo gótico muy importante, a saber, el del incesto, tema muy utilizado por la novela gótica y sus escritores, según Gabriel Eljaiek Rodríguez:

Desde sus inicios, el gótico ha lidiado con el tema del incesto porque su transgresión se considera uno de los tabúes sociales más importantes. Walpole publicó sólo cincuenta copias de The Mysterious Mother en 1768 - que repartió entre sus conocidos- debido a las relaciones incestuosas de sus protagonistas; asimismo, Mary Shelley trabajó el tema del incesto entre padre e hija en Matilda (1819) texto no tan conocido como Frankenstein, pero de gran importancia. Polidori también incursionó en el tema en su novela Ernestus Berchtold, or The Modern Oedipus (1819), así como Poe, quien lo usó directa e indirectamente en muchos de sus cuentos, entre los que se destaca The Fall of The House Usher (Eljaiek Rodríguez, 2017, p. 100).

Así pues, todo lo que el ser humano trata de reprimir por medio de las prohibiciones en el inconsciente y que aflora en la creación de ambientes, situaciones y personajes extraños y perturbadores, tema por excelencia de la novela gótica, es traído de vuelta, como en el caso de Fernando Vidal Olmos por su obsesión hacía los ciegos en el Informe sobre ciegos: el incesto, la maldad y la crueldad sin límites. Finalmente, y en relación con este análisis, téngase en cuenta que en Sobre héroes y tumbas los aspectos de la novela gótica anteriormente resaltados cobran una notable importancia, no sólo por pertenecer a una tradición literaria que influyó en la modernidad hasta llegar al propio Sábato, sino también por ser una serie de motivos y recursos literarios que le permitieron al autor argentino expresar su obsesión por lo irracional y los aspectos oscuros del inconsciente de la mente humana, los cuales llegarían a su máxima expresión y desarrollo en Abbadón el exterminador, tal como se verá a continuación. 


\section{Aspectos góticos presentes en Abbadón el exterminador}

Abbadón el exterminador narra tres historias que se entrelazan y conectan a lo largo de la novela: la de Sabato, alter ego y representante ficcional del escritor, que sucumbe ante las presiones de los poderes infernales de la secta de los ciegos que impiden que concrete su labor de escritura, llevándolo a la locura y a la muerte; la de Nacho y Agustina Izaguirre, una pareja de hermanos que tienen una relación incestuosa y se relacionan de una forma u otra con Sabato y, finalmente, la de Marcelo Carranza, un joven idealista con tendencias revolucionarias, amigo de Sabato, que es detenido, torturado y asesinado por las fuerzas represivas del Estado argentino. A lo largo de la trama de la novela se suceden una serie de acontecimientos y hechos que no obedecen a un esquema convencional de narración, donde se intercalan apariciones de personajes de las otras novelas de Sábato, tales como Juan Pablo Castel, Alejandra Vidal Olmos, Martín del Castillo, Bruno Bassán, Natalicio Barragán y Quique, entre otros. Hay que destacar que el eje fundamental de la novela, en la medida en que todo lo demás que ocurre en ella está relacionado con él, es el personaje Sabato, el cual representa al escritor Ernesto Sábato en la ficción. A diferencia de su creador, el personaje no lleva su apellido acentuado en la primera sílaba, pero comparte varios de sus rasgos autobiográficos, expresa las opiniones consignadas en los ensayos y novelas anteriores de Ernesto Sábato, los cuales cita como suyos, y está tratando de escribir la novela Abbadón el exterminador, presionado por una obsesión paranoica con las fuerzas demoníacas de la secta de los ciegos que él, según cuenta en Abbadón, ha descrito en el Informe sobre ciegos de Sobre héroes y tumbas por medio del personaje de Fernando Vidal Olmos. Estas entidades lo acosan, impidiéndole terminar su trabajo y están constantemente interfiriendo en él, además de haberlo obligado en el pasado a escribir sus otras dos novelas, tal como se lo confiesa a Bruno Bassán:

Durante años debí sufrir el maleficio. Años de tortura. Qué fuerzas obraron sobre mí no se lo puedo explicar con exactitud; pero sin duda provenientes de ese territorio que gobiernan los Ciegos, y que durante estos diez años convirtieron mi existencia en un infierno, al que tuve que entregarme atado de pies y manos, cada día, al despertar, como en una pesadilla al revés, sentida y aguantada con la lucidez del que está plenamente despierto y con la desesperación del que sabe que nada puede hacer para evitarlo. Y para colmo, teniendo que guardarse para sí mismo los horrores (Sábato, 2011, p. 21).

Estos sucesos inexplicables, que se asemejan en varios aspectos a figuras y motivos de la novela gótica, suceden en la niñez y adolescencia de Sabato en los años 20 en Rojas, su pueblo natal y durante varias estancias en Buenos Aires con el padre de Marcelo Carranza, amigo de su adolescencia, en una vieja mansión de la 
familia Carranza, lugar donde ocurrirá su primer contacto con la secta de los ciegos, por medio de los misteriosos personajes R. y Soledad. R. es un personaje oscuro y enigmático, que está relacionado con la secta de los ciegos y remite al motivo gótico del doble, siendo una especie de doble o desdoblamiento maligno de Sabato, que representa los lados irracionales y oscuros de su mente:

R., siempre detrás, en la oscuridad. Y él siempre obsesionado con la idea de exorcizarlo, escribiendo una novela en la que ese sujeto fuese el personaje principal. Ya en aquel París de 1938, cuando se le reapareció, cuando trastornó su vida (Sábato, 2011, p. 37).

Esta presión proveniente de su inconsciente, simbolizada por R., obliga al personaje Sabato de Abbadón a escribir la novela que será posteriormente Sobre héroes y tumbas, la cual después de una serie de cambios y modificaciones en los personajes originales y en sus acciones, terminará siendo la versión definitiva que será publicada en 1961. R. encarnaría esta tensión de las pulsiones inconscientes de la mente del escritor Sabato, de manera similar a los desdoblamientos que, según Gabriel Eljaiek Rodríguez, ocurren en obras emblemáticas de la literatura gótica tales como El extraño caso del Doctor Jekyll y Mister Hyde (1886) de Robert Louis Stevenson o El retrato de Dorian Gray (1890) de Oscar Wilde, en las que el héroe y el villano son el mismo, producto de la perturbación psicológica o del factor sobrenatural, generando ambigüedad y extrañeza en su comportamiento y actuaciones:

Esta tensión, que funciona como ambigüedad, envuelve a los personajes, que no son completamente buenos o malos, y a las situaciones. Los personajes, aunque estereotípicos- villanos crueles, heroínas en peligro, héroes inútiles-, no son tan planos como parecen, hasta el punto de que en muchas de las novelas y cuentos góticos el protagonista es al mismo tiempo el antagonista, ya sea por procesos psicológicos del personaje o por la intervención de un suceso o ente sobrenatural; es el caso de personajes tan famosos como Jekyll y Hyde o Dorian Gray, héroes y villanos de sus respectivas historias (Eljaiek Rodríguez, 2017, pp. 23-24).

Asimismo, R. anticiparía al Fernando Vidal Olmos de Sobre héroes y tumbas, al tiempo que recuerda también a varios villanos de las novelas góticas, según la descripción que de él hace Sabato a Bruno:

Me pareció alguien vagamente conocido: era de mi misma edad (somos gemelos astrales, me comentaría después, en más de una ocasión, con aquella risa seca que helaba la sangre) y todo en él sugería una gran ave de rapiña, un gran halcón nocturno (y, en efecto, nunca los vería sino en la soledad y las tinieblas). Sus manos eran descarnadas, ávidas, depredatorias, despiadadas. Sus ojos me parecieron grisverdosos que contrastaban con 
una piel oscura. Su nariz era fina pero poderosa y aguileña. A pesar de estar sentado, calculé que debía ser bastante alto y levemente encorvado. Vestía con ropa gastada pero a través de lo raído se veía su aristocracia (Sábato, 2011, p. 259).

Al ser R. una encarnación de la irracionalidad de Sabato, adquiere una apariencia enigmática y perturbadora, de una extraña belleza y gran magnetismo, aspecto que se conectaría y relacionaría con la imagen del villano gótico, figura que va más allá de la novela gótica clásica y que perduró en la tradición literaria europea del siglo XIX a través de varias corrientes, tal como recalca Umberto Eco:

Concretamente, en obras como El castillo de Otranto de Horace Walpole (1764), Vathek de Beckford (1786), El monje de Lewis (1796), El italiano o el confesionario de los penitentes negros de Ann Radcliffe (1797), Melmoth el errabundo de Charles Robert Maturin, desfilan personajes que exhiben una tenebrosa belleza o llevan en el rostro los estigmas de su maldad. El héroe condenado (heredero a menudo del diablo miltoniano) seguirá apareciendo en la pintura y en la literatura más allá del movimiento gótico y perdurará en el romanticismo, realismo y decadentismo. Así son el 'infiel' de Byron (1813) y los distintos malvados que aparecen en Sue, Balzac, Emily Brontë, Hugo, Stevenson, hasta nuestros días (Eco, 2013, p. 282).

Cabe recordar que fueron los misteriosos personajes R. y Soledad quienes introdujeron e iniciaron al adolescente Sabato en 1927, durante su estadía en la casa de los Carranza, en la dimensión de la secta de los ciegos, tal como este se lo relata a Bruno. Soledad, prima lejana de los Carranza, es una muchacha cuya presencia y miradas perturbadoras despiertan en el joven Sabato inquietantes presentimientos, además de ser un claro antecedente del personaje de Alejandra Vidal Olmos en Sobre héroes y tumbas, pero de una manera mucho más oscura y negativa que la convierte en un ser de pesadilla que desafía los parámetros de la realidad:

Alguna vez le había contado a Bruno que Soledad parecía la confirmación de esa antigua doctrina de la onomástica, pues su nombre correspondía con exactitud a lo que era: hermética y solitaria, parecía guardar el secreto de esas Sectas poderosas y sangrientas, cuya divulgación se castiga con el suplicio y la muerte. Su violencia interior estaba como mantenida bajo una presión en una caldera. Pero una caldera alimentada por un fuego helado. Le aclaró, ella misma era un oxímoron, no en el precario lenguaje con que podía describírsela. Más que sus indispensables palabras (o sus gritos sexuales), sus silencios sugerían hechos que no correspondían a lo que habitualmente se llaman 'cosas de la vida', sino a esa otra clase de verdades que rigen las pesadillas. Era un ser nocturno, un habitante de cuevas, y tenía la misma mirada paralizante de las serpientes (Sábato, 2011, p. 400). 
Soledad parece una mezcla del fantasma de las novelas góticas con la mujer fatal de las mismas narraciones. El fantasma en la novela gótica representa el miedo a lo desconocido que representa la muerte y su aparición genera terror y desconcierto por violar las leyes de la naturaleza, aquello que no debería ocurrir, el regreso de un muerto a la vida, en un mundo en donde ya no se cree en lo sobrenatural. Según Miriam López Santos:

El fantasma, ser ambiguo por excelencia, es el arquetipo de los muertos vivientes habitantes del castillo gótico. Su presencia en la literatura es mucho anterior a la aparición del subgénero gótico y se apoyaba en la creencia cristiana de que el regreso de las almas al mundo de los vivos era un fenómeno permitido por Dios y cuyo fin fundamental era la prestación de algún tipo de ayuda a los seres humanos. Sin embargo, esta primigenia concepción positiva del fantasma cambiará con la llegada de la novela gótica. Su aparición va acompañada siempre de un efecto maléfico. De hecho, en el marco de esta novela, estos seres son, ante todo, objetos de terror y como tales son utilizados por los escritores para lograr el deseado efecto de terror (López Santos, 2008, p. 193).

Asimismo, es una suerte de mujer fatal, ya que seduce al joven Sabato con su presencia y el aura de misterio y maldad que la rodea, fuerzas a las cuales no puede resistirse de ninguna manera. Así define Miriam López Santos a esta clase de mujer fatal de la novela gótica, emisaria de las fuerzas del mal y de lo demoníaco:

Frente al hombre atormentando, dispuesto a dejarse convencer por el demonio y abandonado a las maldades del mundo, se yergue un tipo de mujer, a quien la certeza de hacer el mal llena de una exaltación casi contagiosa. Esta mujer fatal que Keats denominó la «belle dame sans merci» es, asimismo, un elemento indispensable dentro de toda trama gótica (López Santos, 2008, p. 199).

El impacto de Soledad en Sabato hace que este la siga una noche por las redes subterráneas de Buenos Aires, en un recorrido que recuerda la inmersión en las cloacas de Fernando Vidal Olmos en el Informe sobre ciegos:

En cierto sentido, aquella marcha silenciosa y delirante se le ocurría (a Sabato) eterna, siguiendo los meandros y las bifurcaciones del pasadizo. Y le asombraba la seguridad con que ella caminaba por la ruta que correspondía al lugar en cuya búsqueda iban. Mientras pensaba, con horror, que quien no conociera el exacto detalle de aquel laberinto jamás podría volver a ver las calles de Buenos Aires, perdido para siempre entre esos hurones, comadrejas y ratas que pronto sentía (más que veía) atravesar fugitivamente delante de ellos hacia sus laberintos aún más asquerosos impenetrables (Sábato, 2011, pp. 401-402).

Nótese en esta descripción de los subterráneos de Buenos Aires la aparición de uno de los escenarios y motivos más importantes y recurrentes de la novela gótica: 
el laberinto. Este ambiente genera con mayor intensidad el ambiente fantástico y onírico en el que Sabato cae irremediablemente, generando confusión y ruptura con la realidad. Por ello, todo este proceso se asocia siempre con la palabra horror, transfigurando por completo la noción de lo que se percibe como lo real en la novela, tal como lo haría el laberinto-cárcel de las novelas góticas, según Miriam López Santos:

El espacio gótico, además de presentarse como una cárcel, adquiere rasgos de laberinto. Esconde una dimensión oculta, la mayoría de las veces subterránea; un mundo siempre caótico que adquiere forma de rompecabezas y donde los caminos o pasillos no conducen a ninguna parte, sino que están trazados para confundir y perder a todo aquel que los recorre (López Santos, 2010, p. 284).

Después de seguir a Soledad por varios pasadizos y túneles, Sabato llega a una cámara oculta, clara reminiscencia de los ambientes subterráneos de la novela gótica, donde se encuentran con R., y este le dice que su destino estará unido de manera indisoluble al mundo de la ceguera y todo lo que esta representa:

- Te diré que también este es uno de los nudos de universo de los Ciegos.

Al cabo de un silencio, añadió:

-Éste será el centro de tu realidad, desde ahora en adelante. Todo lo que hagas o deshagas te volverá a conducir hasta aquí. Y cuando no vuelvas por tu propia voluntad, nosotros nos encargaremos de recordarte tu deber (Sábato, 2011, p. 403).

R. obliga al joven Sabato a tener relaciones sexuales con Soledad, en una extraña ceremonia en la que Soledad se desnuda y al hacerlo se descubre que, en vez de poseer el órgano genital, tiene un ojo gris-verdoso como sexo que Sabato revienta, escena que ha sido analizada desde diversas perspectiva críticas, tales como el influjo del surrealismo o la presencia de doctrinas esotéricas en la novela de Ernesto Sábato; a partir de entonces su destino queda irremediablemente marcado por el influjo maligno de la secta de los ciegos, quienes lo persiguen en 1938 cuando es becario del laboratorio Curie en París, y en Buenos Aires en 1972 cuando es un escritor consagrado. Por esta razón los escenarios que aparecen en Abbadón, presentan, por un lado, una apariencia realista en la que se mueven los protagonistas y, por otro, un ámbito onírico de pesadilla, similar en varios aspectos a los de las novelas góticas, que se va acelerando y apoderando de los personajes a medida que progresa el relato. Este segundo universo va surgiendo de manera sutil del mundo cotidiano de todos los días, hasta el punto de convertir y trastocar lo habitual en algo insólito e inquietante que desafía las leyes de la lógica y de la racionalidad imperantes para explicar la realidad, tal como lo afirma el propio personaje Sabato: 
¿Pero si esos monstruos invisibles, una vez invocados, se lanzaban sobre nosotros sin que pudiéramos dominarlos? O nuestro conjuro no es el exacto y resulta incapaz de abrir las puertas de los infiernos; ¿o es exacto, y entonces corremos el riesgo de la locura o de la muerte? (Sábato, 2011, p. 25).

Esta serie de alucinaciones y visiones que sufre Sabato terminarán llevándolo a la locura y a la muerte, tal como les ocurre a varios personajes de las novelas góticas que sufren el influjo de lo demoníaco en su existencia. Esto se nota claramente cuando Sabato, después de perseguir a R. por los subterráneos de Buenos Aires en 1972, emerge de ellos tras grandes dificultades, vuelve a su casa en el pueblo de Santos Lugares y se ve a sí mismo en su estudio, sin que su doble, el otro Sabato, pueda advertir su presencia, como si se tratara de un sueño o de una pesadilla:

Los dos estaban solos, separados del mundo. Y, para colmo, separados entre ellos mismos. De pronto observó que de los ojos del Sabato sentado habían comenzado a caer algunas lágrimas. Con estupor sintió entonces que también por sus mejillas corrían los característicos hilillos fríos de las lágrimas (Sábato, 2011, pp. 408-409).

El desdoblamiento y la posterior metamorfosis de Sabato en un murciélago, animal que simboliza la oscuridad y la ceguera a las que se ve sometido por los poderes malignos de la secta de los ciegos, representan esa entrega total del escritor a las obsesiones irracionales que han alimentado su obra novelística, pulsiones que lo conducen a la aniquilación y a la locura en una atmósfera de pesadilla dominada por fuerzas demoníacas. En este sentido es que se acentúa de manera notoria lo diabólico y lo sobrenatural de los acontecimientos asociados a una realidad que no se puede calificar como normal, y que termina perteneciendo al ámbito de lo gótico y de lo onírico, tal como lo afirma Gemma Roberts:

De esta manera, después de la entrega de Sabato a las fuerzas nocturnales de la creación novelística, queda efectuado el desdoblamiento y la enajenación definitivos del autor de Abbadón: de una parte, el Sabato transformado en horrible murciélago (25), monstruo de su arte, ignorado por todos los de su casa e invisible a todos menos a su perro, que con percepción animal para lo diabólico y lo sobrenatural, le ladra con los pelos erizados; por otra parte, el Sábato existente, solitario e incomprendido: 'Los dos estaban solos, separados del mundo. Y, para colmo, separados entre ellos mismos' (473). El uno, el artista, condenado al recinto hermético de la novela, mundo infernal y monstruoso, porque aspira a la aniquilación del tiempo; el otro, el Sábato de la vida real, condenado a la temporalidad y en espera de su propia aniquilación en la muerte (Roberts, 1983, p. 534).

Finalmente, la presencia de lo sobrenatural, característica de la novela gótica, así como las figuras y motivos góticos anteriormente mencionados, representan que 
Sabato no logra superar la prueba que las fuerzas del inconsciente, simbolizadas en la secta de los ciegos, realizan en él, a saber, su influjo maligno que el personaje no puede llegar a asimilar y a sintetizar en un equilibrio armónico, de tal manera que éstas se apoderan de él por completo, conduciéndolo a la locura y a la destrucción.

\section{Conclusiones}

Este artículo es apenas un primer y breve recuento sobre los aspectos de la novela gótica que aparecen en las novelas de Ernesto Sábato, incluyendo su primera novela El túnel (1948), la cual no fue analizada en esta ocasión por falta de espacio. Queda todavía mucho por explorar sobre este tema y sobre la poderosa influencia que la corriente literaria de la novela gótica pudo ejercer en la obra novelística de escritor argentino. En efecto, el estudio de esta corriente y su incidencia en las novelas de Ernesto Sábato podría dar luz a trabajos de investigación sumamente interesantes y esclarecedores, que ampliarían este primer paso que hemos dado.

En conclusión, los aspectos de la novela gótica presentes en Sobre héroes y tumbas y en Abbadón el exterminador, servirían como soporte para el tema de lo irracional en la obra de Ernesto Sábato, y a su premisa que afirma la existencia de elementos que escapan por completo a la lógica y a la racionalidad que se han impuesto en Occidente, mostrando también las distintas modificaciones y adaptaciones que estas figuras y motivos han tenido a lo largo de la historia hasta llegar al día de hoy, en el cual, a pesar de la modernidad, todavía encarnan en la literatura los rasgos más extraños, oscuros y malvados de la existencia humana.

En Sobre héroes y tumbas los aspectos de la novela gótica representan una contraparte al presente de la Argentina de los años cincuenta del siglo XX, frente a un pasado oscuro, pasado que es negado y reprimido a toda costa. Por tanto, emerge e irrumpe con fuerza rompiendo la normalidad de lo cotidiano; al mismo tiempo, lo siniestro y lo ominoso, según la terminología freudiana, habla de esos miedos a enfrentar las pulsiones del inconsciente, que adquieren rasgos fantásticos en los ambientes extraños y sombríos de la casa de los Olmos experimentados por Martín del Castillo. También cabe destacar que el relato de Fernando Vidal Olmos acerca de la supuesta secta demoníaca de los ciegos en Informe sobre ciegos representaría la locura y las obsesiones incontrolables del inconsciente que estallan por el incesto, motivo de gran importancia en la novela gótica.

Por otro lado, en Abbadón el exterminador, los personajes de R. y Soledad que acosan al escritor Sabato, así como los escenarios subterráneos, los ambientes oníricos y la fuerza sobrenatural de la secta de los ciegos que conducen a la transformación en murciélago y a la locura y a la muerte a este personaje, suponen una 
nueva manera de aproximarse a lo gótico en la obra de Ernesto Sábato, al tiempo que nos alertarían, como la hace la novela gótica clásica, del peligro que depara a la humanidad el dejar de creer y de aceptar el influjo de lo irracional proveniente del inconsciente en el ámbito contemporáneo, negación que puede llegar al punto de influir de manera determinante, e incluso negativa, en el ser humano.

Por último, se podría afirmar que Ernesto Sábato utiliza estas figuras, temas y motivos góticos en el sentido literario como soporte a una escritura destinada a exponer su pensamiento y su crítica a un mundo en el que prima lo racional sobre lo irracional, en el cual otro tipo de creencias que no estén fundamentadas en la racionalidad ya no tienen valor, por lo que deben refugiarse en el arte y en la literatura, para expresar distintas formas de entender la realidad, tal como ocurrió en el caso de la novela gótica.

\section{Referencias bibliográficas}

1. Cueto, R. (2010). ¿Qué es lo 'gótico'? El adjetivo que se convirtió en un género. En A. J. Navarro (Ed.), Pesadillas en la oscuridad: el cine de terror gótico (pp. 17-61). Madrid: Valdemar.

2. Eco, H. (2013). Historia de la Fealdad. Barcelona: Lumen.

3. Eljaiek Rodríguez, G. (2017). Selva de fantasmas: el gótico en la literatura y cine latinoamericanos. Bogotá: Editorial Pontificia Universidad Javeriana.

4. Freud, S. (1992). Volumen 17 (1917-19). De la historia de una neurosis infantil y otras obras. Buenos Aires: Amorrortu Editores.

5. Gónzalez Moreno, B. (2007). Lo sublime, lo gótico y lo romántico: la experiencia estética en el romanticismo inglés. Cuenca: Universidad de Castilla-La Mancha.

6. López Santos, M. (2008). Teoría de la novela gótica. Estudios humanísticos. Filología, 30, pp. 187-210.

7. López Santos, M. (2010). Ampliación de los horizontes cronotópicos de la novela gótica. Signa: revista de la Asociación Española de Semiótica, 19, pp. 273-292.

8. Lovecraft, H, P. (1973). Supernatural Horror in Literature. New York: Dover Publications.

9. Matamoro, B. (1983). En la tumba de los héroes. Cuadernos Hispanoamericanos, Tributo a Ernesto Sábato, pp. 391-393, pp. 485-498.

10. Roberts, G. (1983). Presencia de lo demoníaco en Abaddón el exterminador, de Ernesto Sábato. Cuadernos Hispanoamericanos, Tributo a Ernesto Sábato, pp. 391-393, pp. 526-536.

11. Sábato, E. (2000). Sobre héroes y tumbas. Bogotá: Seix Barral.

12. Sábato, E. (2011). Abbadón el exterminador. Barcelona: Austral/Seix Barral.

13. Sánchez López, P. (2006). Elementos fantásticos en la narrativa de Ernesto Sábato. Revista Semiosis, 4, pp. 87-102.

14. Walpole, H. (2014). The Castle of Otranto: A Gothic Story. Oxford: Oxford University Press. 